\title{
Hearing loss in Grand Prix motorcyclists: occupational hazard or sports injury?
}

\author{
A. W. McCombe FRCS and J. Binnington MBAAT* \\ Department of Otolaryngology, Plymouth General Hospital, Plymouth, UK, and *Cottage Street Hearing \\ Centre, Brierly Hill, West Midlands, UK
}

\begin{abstract}
The prevalence of noise-induced hearing loss (NIHL) in current motorcycle grand prix racers was investigated. A total of 44 riders was randomly recruited and underwent interview, otological examination and pure tone audiometry. The median age was 28 (range 18-37) years and median racing experience was 10 (range 2-21) years. Twenty riders $(45 \%)$ had hearing losses greater than expected for age matched controls. Not surprisingly this hearing deficit tended to increase with racing experience $(r=0.5, t=2.51,19$ d.f., $P<0.05)$. Only 17 riders $(39 \%)$ were regular users of earplugs and only nine had used them for most of their racing careers. There is a need to raise awareness to this problem and increase the use of earplugs to avoid NIHL in grand prix motorcyclists.
\end{abstract}

Keywords: Hearing loss, motorcyclists, wind noise

It has become increasingly apparent over the past 10-15 years that motorcyclists are exposed to noise levels far in excess of those that would be permitted in an industrial setting ${ }^{1}(85 \mathrm{~dB}(\mathrm{~A})$ : Health and Safety at Work Act $1991^{2}$ ). This noise arises, not from the machinery, for which adequate controls exist ${ }^{3}$, but from turbulent air flow around the rider's helmet. This low frequency 'wind noise' reaches $90 \mathrm{~dB}(\mathrm{~A})$ at about $40 \mathrm{~m}$.p.h. and increases linearly with $\log _{10}$ speed (m.p.h.) to reach levels of $110 \mathrm{~dB}(\mathrm{~A})$ at 100 m.p.h. ${ }^{4}$. At 150 m.p.h., a not uncommon speed for a Grand Prix motorcyclist, noise levels of the order of $120 \mathrm{~dB}(\mathrm{~A})$ would be expected.

Regular exposure to sounds of this magnitude will lead to noise-induced hearing loss (NIHL). NIHL can be seen by its effects on the audiogram of affected individuals. Initially it will cause a 'dip' in the audiogram between the frequencies of 3 and $6 \mathrm{kHz}$. As the damage progresses, the hearing loss spreads to involve the frequencies on either side of this region with a tendency for the higher frequencies to be more severely affected ${ }^{5}$.

Despite the recognition of the potential risk to motorcyclists' hearing, there are no published audiological surveys in existence. We have chosen to investigate Grand Prix motorcyclists in the first instance as this group of riders tends to operate at

Address for correspondence: Mr A. W. McCombe, Senior Registrar, Department of Otolaryngology, Southmead Hospital, Westbury-on-Trym, Bristol BS10 5NB, UK

(C) 1994 Buterworth-Heinemann Ltd. 0306-3674/94/010035-03 exceptionally high speeds, both in testing and racing, and consequently will have consistently high noise exposures.

\section{Materials and methods}

There were 103 motorcyclists registered on the International Racing Team's Association (IRTA) list as licenced Grand Prix riders in 1992. From this list, riders were randomly recruited to the study over the two rest days before testing for the 1992 British Grand Prix at Donington Park.

These riders were then interviewed with regard to previous noise exposure, previous ear pathology, riding experience and the use of earplugs. An otological examination and tympanogram were then performed. The tympanometer was an Electromedics 85 AR (Electromedics, Hudson, USA). Any rider with a previous history of noise exposure or ear pathology, or abnormal findings on examination and tympanogram, was excluded from the study at this stage.

Next a manual pure-tone audiogram was performed ${ }^{6}$ using a Kamplex AD27 Audiometer (Interacoustics, Assens, Denmark) in a mobile sound proof room (Figure 1) designed to meet the standard DHSS CE (76) D532/74 (i.e. sound level $<25 \mathrm{~dB}(\mathrm{~A})$ ). Sound levels were checked using a Castle CS182B sound level meter $\mathrm{db}(\mathrm{A})$ (Castle Associates, Scarborough, UK) and found to meet this standard except during the take off and landing of aircraft at the East Midland's airport. Testing was suspended during these short periods.

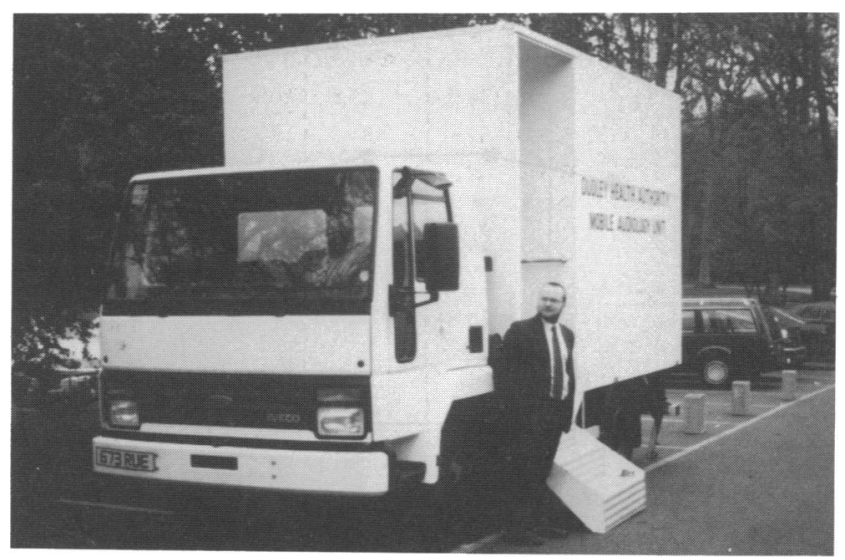

Figure 1. Mobile sound-proof facility 
The audiometric data were then compared with control data for non-noise exposed, age and sex matched controls obtained from the large population data of Robinson and Sutton ${ }^{7}$. Any rider displaying a conductive loss of more than $10 \mathrm{~dB}$ was excluded from this analysis.

Statistical analysis was performed using the Students $t$ test.

\section{Results}

Originally 50 riders were recruited to the study of which six were ultimately excluded - five for previous noise exposure and one with a conductive hearing loss.

All the data presented are based on the remaining 44 riders; all men. The median age was 28 (range 18-37) years and racing experience 10 (range 2-21) years.

A high-frequency dip in the audiogram consistent with noise exposure was found in 27 riders $(61 \%)$ a typical example is shown in Figure 2.

The median audiogram with 25th and 75th centiles is shown in Figure 3. Also shown is the control audiogram for 30-year-old men with no previous noise exposure. These audiograms are significantly different at all frequencies $(t>3.5, P<0.001$, at all frequencies).

Twenty riders (45\%) were found to have audiograms that fell below the 95th centile of the control audiogram at more than one frequency. There was a not unexpected correlation between the degree of hearing loss and length of racing experience among this group ( $r=0.5, t=2.51,19$ d.f., $P<0.05$ ).

Earplugs were used regularly by 17 riders $(39 \%)$ but only nine $(20 \%)$ had used them for more than half

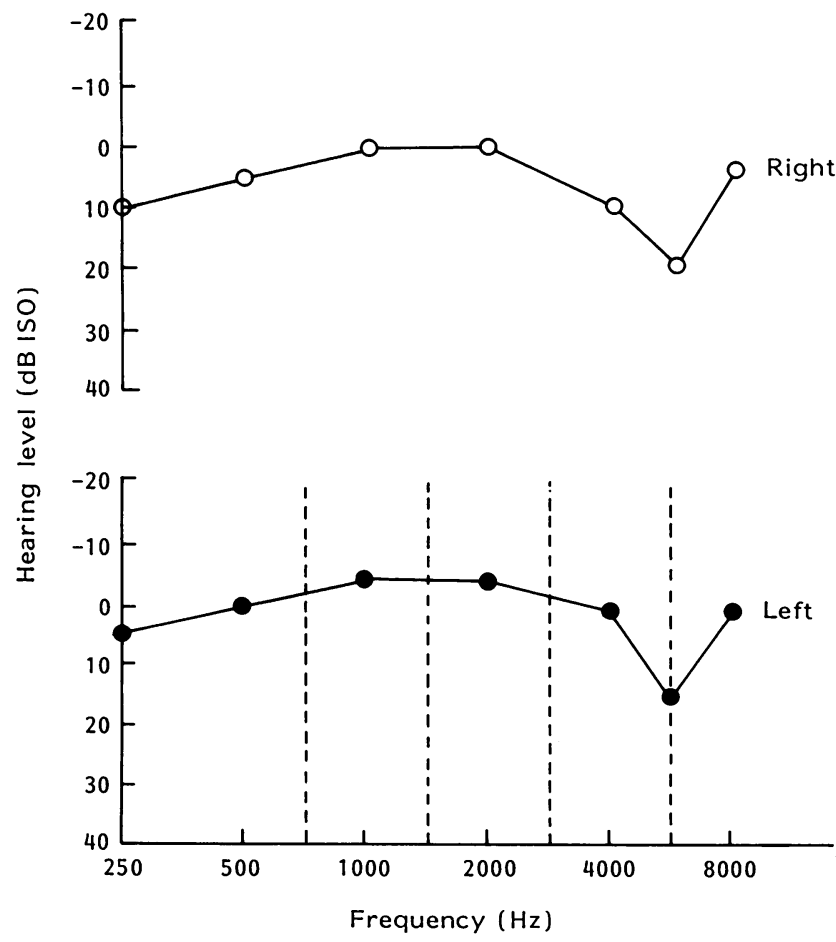

Figure 2. Typical audiogram of Grand-Prix motorcyclist showing air conduction in right $(O)$ and left $(O)$ ears

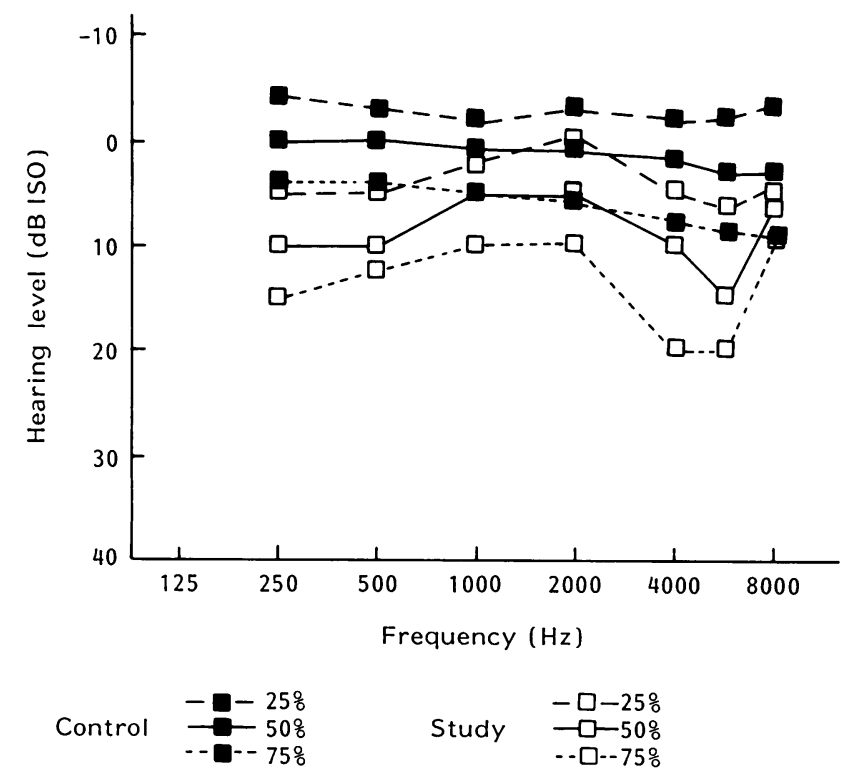

Figure 3. Median audiograms of Grand-Prix motorcyclists and control group with 25 th and 75 th centiles

of their racing careers. Unfortunately, because of the relatively small numbers involved and short time of use in some cases, analysis of the effects of earplugs on hearing loss was not possible.

\section{Discussion}

We believe this to be the first published study to investigate the prevalence of noise-induced hearing loss (NIHL) among motorcyclists. We have shown without doubt that the average hearing of Grand Prix motorcyclists is significantly worse than age matched, non-noise exposed controls. The careful screening of our test group to ensure no other noise exposure allows us to conclude that any hearing loss is due to motorcycling. Furthermore, we would define the prevalence of NIHL among this group as $45 \%$, that is the proportion of riders whose hearing was worse than the 95th centile of the control group.

The standardized data of Robinson and Sutton ${ }^{7}$ are based on an analysis of all published data from a variety of international sources and represent a technical report to the International Organization for Standardization (ISO) technical committee 43. As such these represent ideal control data for our study group who themselves are of mixed international origin, although predominantly European and North American.

NIHL is an occupationally prescribed disease according to the Health and Safety at Work Act (1989) when noise levels at the work place exceed $85 \mathrm{~dB}(\mathrm{~A})$ for an 8-h day. There is no doubt that professional Grand Prix motorcyclists are often exposed to noise levels well in excess of this value.

A sports injury may be defined as any injury obtained during participation in a sporting activity. The NIHL that occurs in these riders fits this definition. However, whether this problem is considered an occupational hazard or a sports injury, in both fields the use of protective equipment is 
endorsed and encouraged ${ }^{8,9}$. In fact, in motorcycle racing, appropriate protective equipment is essential to ensure eligibility to compete ${ }^{3}$. Earplugs represent a suitable protective device for either discipline. They have long been established for use in industry ${ }^{8}$, and we have recently demonstrated their efficacy for the motorcyclist ${ }^{10}$.

We were therefore disappointed to discover that only nine riders $(20 \%)$ were long-term earplug users. When questioned about the possible use of earplugs, as well as displaying a low awareness of the potential risks of noise damage, many riders expressed the inevitable concern about the perception of other environmental sounds, in particular the engine and exhaust of the bikes. However, comments from those riders who use earplugs and our own research ${ }^{11}$ indicate that the hearing protected rider is probably at a slight advantage in this regard.

As a consequence of this study, we feel that awareness of this problem needs to be raised among this group of sportsmen. In addition, we would strongly recommend earplugs be considered as essential protective equipment for motorcycle racers at all levels in an effort to prevent the occurrence of noise damage.

\section{Acknowledgements}

We wish to acknowledge the following: Dudley Health Authority for the provision of the mobile sound proof booth; Mr P. Richards
FRCS, Mr M. Trimby of IRTA and Mr R. Fearnell of Donington Park for their help and support in allowing us to undertake this investigation; Mrs J. Clinton for typing the manuscript, and most of all to the riders for their time, patience and cooperation.

This study was supported by a grant from the Plymouth Postgraduate medical school.

\section{References}

1 Ross BC. Noise exposure of motorcyclists. Ann Occup Hyg 1989; 33: 123-7.

2 Health and Safety Executive. Noise at work. The noise at work regulations 1989. London, UK: HMSO, 1989.

3 Auto-cycle Union. ACU 1993 Handbook. Rugby, UK: ACU, 1993.

4 McCombe AW, Binnington JD, Bose R. Wind noise and motorcyclists (Abstract). Clin Otolaryngol 1993; 18: 436.

5 Noise and hearing loss. NIHL consensus development conference statement, 22-24 January 1990; 8 (1).

6 British Society of Audiology/British Association of Otolaryngologists. Recommended procedures for pure-tone audiometry using a manually operated instrument. $\mathrm{Br} J$ Audiol 1981; 15: 213-16.

7 Robinson DW, Sutton GJ. Age effect in hearing - a comparative analysis of published threshold data. Audiology 1979; 18: 320-34.

8 Health and Safety Executive. Noise at work. Noise guides 3-8. London, UK: HMSO, 1990.

9 McLatchie GR. The value and limitations of protective equipment. In: GR McLatchie, ed. Essentials of Sports Medicine. Edinburgh, Scotland: Churchill Livingstone, 1986.

10 McCombe AW, Binnington JD. Hearing protection for motorcyclists. Clin Otolaryngol.

11 Binnington JD, McCombe AW, Harris M. Warning signal detection and the acoustic environment of the motorcyclist. $\mathrm{Br} J$ Audiol (in press).

The appointment of an Honorary Medical Officer is a newly created position and is intended to run for a two vear term. beginning 1 September 1994. The appointed person will receive close co-operation from the England Netball Physiotherapist. Coaches and other members of the Sports Science team.

She/he will be expected to provide advice and guidance. and referrals to other medical specialists as appropriate: to provide treatment covenng a wide range of issues. including - use and abuse of medications. travel medicine. medical and biomechanical screening, and management of injuries.

The successful applicant will hold an appropnate medical qualification with post-graduate expenence in the field of sports medicine - preferably with some expenence of netball-reiated injuries. and some knowledge of national sports governing bodies.

Applications with curnculum vitae must be submitted by Fnday April 15th and interveews will be held on Saturday May 7th.

For application forms and further details please contact:

Mrs E Nicholl. Chief Executive. All England Netball Association.

Netball House. 9 Parnes Park. Hitchun. Herts SG5 IEH (Tel: (1)462-42344 Fax 0462-442343) 